\title{
Multi-instrument Pollution Abatement from Multiple Sources: The Case of Nitrogen Pollution in Groundwater
}

\author{
Kimberly Burnett ${ }^{1}$, James Roumasset ${ }^{1,2}$, Christopher A. Wada ${ }^{*}$ \\ ${ }^{1}$ University of Hawai'i Economic Research Organization, 2424 Maile Way, Saunders Hall 540, Honolulu, HI \\ 96822, USA; ${ }^{2}$ University of Hawai'i Department of Economics, 2424 Maile Way, Saunders Hall 542, Hono- \\ lulu, HI 96822, USA
}

Received: April 29, 2012 / Accepted: June 27, 2012

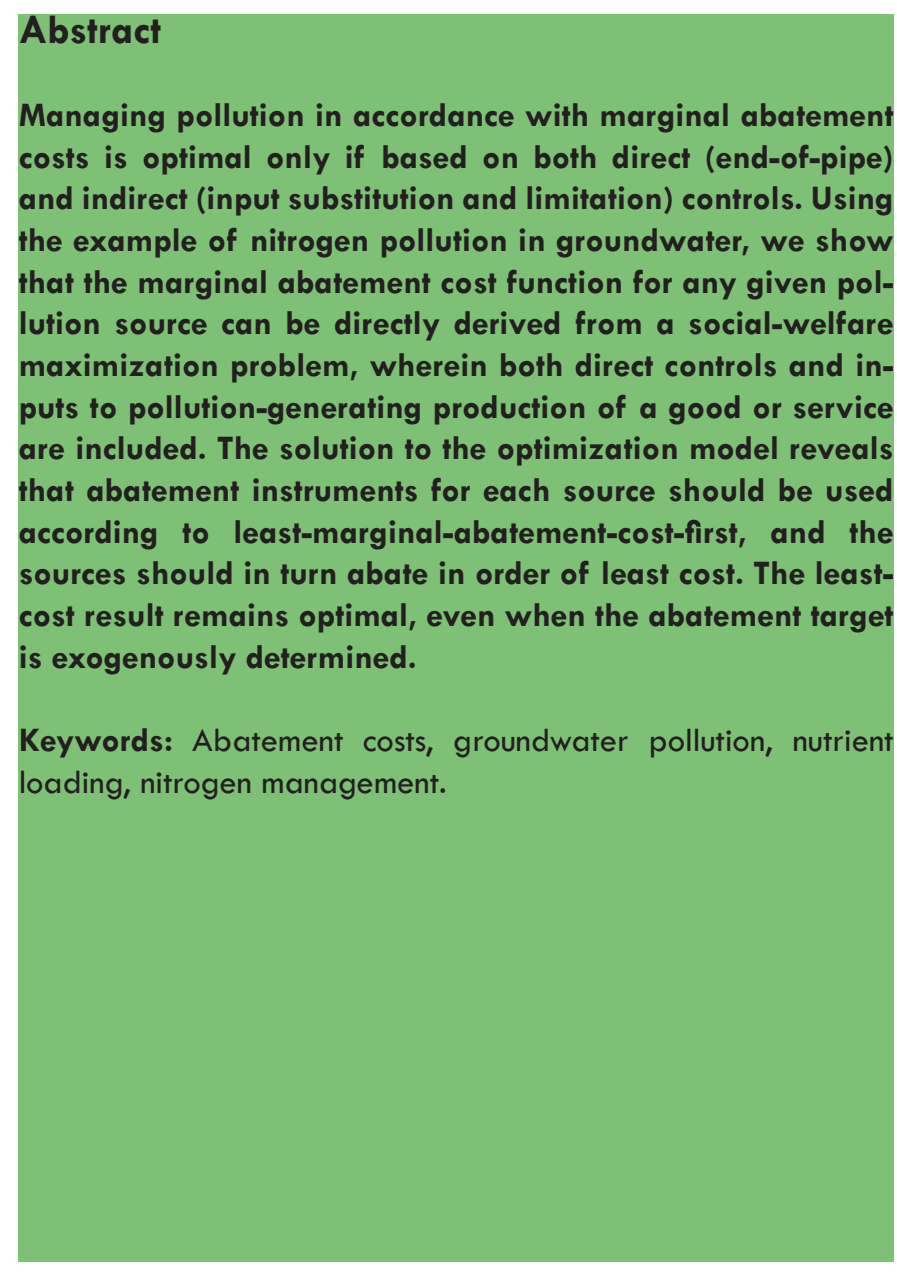

* Corresponding author: cawada@hawaii.edu

\section{Introduction}

Pollution management proposals often describe control strategies in terms of abatement and associated costs without detailed explanations of exactly how the marginal abatement cost (MAC) functions are derived. Yet, such management strategies can only be welfare-maximizing if the MAC functions are themselves derived from an optimization problem which takes into account each source's costs-including reductions in benefits such as profits - of abating pollution. As an alternative to assuming a functional form for abatement costs, we show that the MAC function can be directly derived from a social-welfare maximization problem, wherein controls include both abatement instruments and inputs to pollution-generating production of a good or service. In doing so, we also describe a procedure for optimally managing pollution when multiple vectors of abatement are available, using the example of nitrogen pollution in groundwater. In some cases, however, quantification of environmental damages generated by the relevant sources of pollution is not feasible, thus rendering the described approach impracticable. We discuss an alternative target-setting approach, according to which abatement instruments should be implemented in the order of least-MAC to achieve the exogenously determined abatement target.

Over the past few decades, three alternatives to assuming a separable abatement cost function have been developed. The "dirty good" approach (Bovenberg and de Mooij, 1994) models emissions as proportional to produced output, thus precluding the treatment of inputs as distinct abatement instruments. The "dirty input" approach (Bovenberg and Goulder, 1996), which 
treats emissions as proportional to a pollution-generating input (e.g. coal), allows for abatement by input substitution but omits end-of-pipe treatment. In both cases, abatement costs need not be stated as a separate function. One simply solves for the socially optimal output and input levels, along with the Pigouvian tax needed to implement the social optimum as an equilibrium. A more general formulation treats emissions as an input to the production function (e.g. Montgomery, 1972; Nordhaus, 2008). Again, the solution involves optimal output, inputs, and emissions; we do not need a separate abatement cost function. While general, however, the production function approach is silent on how to derive the relationship between emissions and output.

Many studies, e.g. in the context of mitigating climate-change (Metcalf, 2009; Murray et al., 2009), discuss how the shapes of marginal benefits and costs of abatement determine optimal policies but simply take MAC as given. A few authors have derived an abatement cost function, albeit under somewhat restrictive conditions. McKitrick (1999) derives an MAC function, taking emissions as a function of output. Such a setup implies end-ofpipe treatment as the single instrument, i.e. it does not allow explicitly for input substitution. Yiridoe and Weersink (1998) provide an interesting application for the case of farm management decisions when adjustments can be made at both the intensive (e.g. fertilization rates) and/or the extensive margin (e.g. crop choice and rotation), but do not consider the more general problem involving input substitution (e.g. different types or methods of fertilization) and end-of-pipe technologies. Thus, the question of how to abate using multiple instruments across multiple firms/ sources has not, to our knowledge, been adequately addressed in the literature.

In the sections that follow, we develop a general analytical model for $m$ sources, $n$ pollution-generating inputs, and an abatement technology (e.g. end-of-pipe treatment) and derive the marginal abatement cost curve in continuous time'. The general results are then discussed in the context of nitrogen pollution to groundwater at a watershed scale and consequently to nearshore ecosystems. The developed framework is transferable to other regions and other types of pollution to the extent that it highlights the data necessary for implementing an abatement model with the objective of welfare maximization. Specifically, a planner would need data to parameterize a pollution transport function and production function for each source, input and output prices for each source, information about the efficacy of end-of-pipe treatments as well as their costs, and a damage function or pollution target.

\section{Materials and Methods}

\section{A General Model of Pollution Abatement}

In the following section, we focus on deriving the MAC function of pollution to a single receptor ${ }^{2}$ from $i=1, . ., m$ sources, each of which use $j=1, \ldots, n$ inputs for the production of a consumable good. In addition to input substitution, each source can implement an end-of-pipe abatement instrument $b^{i}$ at unit cost $c^{i}$. Pollution can also be decreased by reducing output $y^{i}$, although decisions to increase or decrease output are inextricably tied to the choice of inputs. Each firm has a unique production function $F_{i}\left(x^{i 1}, x^{i 2}, \ldots\right.$ $\left.x^{\text {in }}\right)$, and the vector of inputs for each firm need not be identical. Because the distance from each source to the receptor varies, the amount of pollution that actually arrives as a result of using a unit of a particular input $j$ will depend on the source. This heterogeneity is captured by source-specific transport functions $T_{i}\left(x^{i 1}, x^{i 2}, \ldots x^{i n}, b^{i}\right)$. The total amount of effective pollution from source $\mathrm{i}$ is then $Z^{i}=z^{i}-G_{i}\left(b^{i}\right)$, where $z^{i}=T_{i}(\bullet)$, and the function $G$ captures the effectiveness of the end-of-pipe instrument. Damages are increasing and convex in total received pollution, i.e. $D^{\prime}\left(\sum_{i} Z^{i}\right)>0$ and $D^{\prime \prime}\left(\sum_{i} Z^{i}\right) \leq 0$. The manager's problem is to choose production inputs and the end-of-pipe instrument for each source to maximize aggregate profits net of end-of-pipe and damage costs:

$$
\text { (1) } \max _{x^{i j}, b^{i}} V, V=\sum_{i=1}^{m}\left[p^{i} y^{i}-\sum_{j=1}^{n}\left(w^{j} x^{i j}\right)-c^{i} b^{i}\right]-D\left(\sum_{i=1}^{m} Z^{i}\right)
$$

subject to

$$
\begin{aligned}
& \text { (2) } y^{i}=F_{i}\left(x^{i 1}, \ldots, x^{i n}\right) \\
& \text { (3) } Z^{i}=z^{i}-G_{i}\left(b^{i}\right) \\
& \text { (4) } z^{i}=T_{i}\left(x^{i 1}, . ., x^{i n}, b^{i}\right)
\end{aligned}
$$

where $p^{i}$ and $w^{i}$ are the exogenous output and factor input prices respectively.

\section{The Static Optimization Solution Procedure}

The maximization problem can be simplified by substituting the equality constraints (Eq. 2-4) into the objective function (Eq. 1) as follows:

(5) $\underset{x^{i j}, b^{i}}{\operatorname{aax} L}, L=\sum_{i=1}^{m}\left[p^{i} F_{i}\left(x^{i 1}, \ldots, x^{i n}\right)-\sum_{j=1}^{n}\left(w^{j} x^{i j}\right)-c^{i} b^{i}\right]-D\left[\sum_{i=1}^{m}\left(T_{i}\left(x^{i 1}, \ldots, x^{i n}, b^{i}\right)-G_{i}\left(b^{i}\right)\right)\right]$

Using standard calculus, one can derive the necessary conditions $\forall i, j$ s follows ${ }^{3}$ :

$$
\begin{array}{ll}
\text { (6) } \frac{\partial L}{\partial x^{i j}}=p^{i} \frac{\partial F_{i}}{\partial x^{i j}}-w^{j}-D^{\prime}(\bullet) \frac{\partial T_{i}}{\partial x^{i j}} \leq 0 & \text { if }<\text { then } x^{i j}=0 \\
\text { (7) } \frac{\partial L}{\partial b^{i}}=-c^{i}+D^{\prime}(\bullet)\left[\frac{\partial T_{i}}{\partial b^{i}}-G_{i}^{\prime}\left(b^{i}\right)\right] \leq 0 & \text { if }<\text { then } b^{i}=0
\end{array}
$$

\footnotetext{
While some have stressed the importance of modeling discrete choices of abatement technologies in applied analysis (Fullerton et al., 1997), we feel that a standard continuous model is useful for building more general intuition.

${ }^{2}$ Inasmuch as the framework is motivated by the problem of nitrogen from various sources polluting a single bay, it does not allow for damages at multiple receptor locations. In other instances, however, emissions from a single source may be dispersed in ways that affect multiple geographic locations, sometimes crossing jurisdictional boundaries. While beyond the scope of the current analysis, further generalization of the model to allow for receptor-specific marginal damage cost functions is essential for characterizing multiple-receptor and transboundary pollution problems.

${ }^{3}$ The necessary conditions are also sufficient, provided that the Hessian matrix of the production function is negative semidefinite.
} 


\section{Results}

\section{Derivation of the Marginal Abatement Cost Curve}

For each source $i$, the vector of $n$ inputs should be chosen to equate marginal benefits and marginal costs (Eq. 6). That is input i should be used until its marginal contribution to profits is exactly offset by its marginal contribution to pollution damage costs. Equivalently, the equimarginality condition requires that the marginal cost of reducing pollution by one unit via a decrease in input $i$ should be equal to the resulting marginal reduction in damage, i.e. for each source $i$

(8) $D^{\prime}(\bullet)=\frac{p^{i} \partial F_{i} / \partial x^{i 1}-w^{1}}{\partial T_{i} / \partial x^{i 1}}=\frac{p^{i} \partial F_{i} / \partial x^{i 2}-w^{2}}{\partial T_{i} / \partial x^{i 2}}=\cdots=\frac{p^{i} \partial F_{i} / \partial x^{i n}-w^{n}}{\partial T_{i} / \partial x^{i n}}$

If this were not the case, one could decrease total environmental damage by substituting inputs, while maintaining the same level of profit. The numerators in Eq. 8 each measure the change in profit per unit of input and the derivatives in the denominators convert those figures into dollars per unit of pollution to be consistent with the marginal damage costs.

The end-of-pipe instrument should be utilized only if the marginal cost of doing so is no greater than the marginal damage cost at the optimum, and if the condition is satisfied, the endof-pipe instrument should be employed until its marginal cost is exactly equal to the marginal damage cost:

$$
\text { (9) } D^{\prime}(\bullet)=\frac{c^{i}}{\partial T_{i} / \partial b^{i}-G_{i}^{\prime}\left(b^{i}\right)}
$$

The denominator on the right hand side of Eq. 9 converts the unit cost of end-of-pipe treatment to dollars per unit of pollution. At an interior solution, i.e. when all of the controls are positive, Eq. 6 and 7 both hold with equality, which implies that the marginal cost of pollution reduction is equal for changes in any of the production inputs and for the end-of-pipe instrument. Moreover, the marginal costs are also equal to the marginal damage cost.

Proposition 1: If production by source $i$ is positive at the optimum, the end-of-pipe instrument is used only if its marginal cost of pollution reduction is equal to that of the production inputs.

Proof: Suppose that $b^{i}>0$ and that

$$
\frac{c^{i}}{\partial T_{i} / \partial b^{i}-G_{i}^{\prime}\left(b^{i}\right)}>\frac{p^{i} \partial F_{i} / \partial x^{i 1}-w^{1}}{\partial T_{i} / \partial x^{i 1}}=\cdots=\frac{p^{i} \partial F_{i} / \partial x^{i n}-w^{n}}{\partial T_{i} / \partial x^{i n}} .
$$

From Eq. 8, we also know that the right hand side of the inequality must be equal to $D^{\prime}(\bullet)$ which implies $-c^{i}+D^{\prime}(\bullet)\left[\partial T_{i} / \partial b^{i}-G_{i}^{\prime}\left(b^{i}\right)\right]<0$, which is consistent with condition Eq. 7 only if $b^{i}=0$, a contradiction.

Suppose instead that $b^{i}>0$ and that

$$
\frac{c^{i}}{\partial T_{i} / \partial b^{i}-G_{i}^{\prime}\left(b^{i}\right)}<\frac{p^{i} \partial F_{i} / \partial x^{i 1}-w^{1}}{\partial T_{i} / \partial x^{i 1}}=\cdots=\frac{p^{i} \partial F_{i} / \partial x^{i n}-w^{n}}{\partial T_{i} / \partial x^{i n}} .
$$

But that implies $-c^{i}+D^{\prime}(\bullet)\left[\partial T_{i} / \partial b^{i}-G_{i}^{\prime}\left(b^{i}\right)\right]>$, Qwhich is inconsistent with Eq. 7.

That leaves only the possibility that the marginal abatement costs are equal, i.e. $\frac{c^{i}}{\partial T_{i} / \partial b^{i}-G_{i}^{\prime}\left(b^{i}\right)}=\frac{p^{i} \partial F_{i} / \partial x^{i 1}-w^{1}}{\partial T_{i} / \partial x^{i 1}}=\cdots=\frac{p^{i} \partial F_{i} / \partial x^{i n}-w^{n}}{\partial T_{i} / \partial x^{i n}}$ for $b^{i}>0$.

The marginal abatement cost (MAC) can be interpreted as either the marginal cost of reducing pollution by one unit or the marginal benefit of generating an additional unit of pollution. Supposing that the transport functions are invertible, each production input can be written as a function of pollution and the levels of the other inputs, i.e.

$$
\text { (10) } x^{i j}=x^{i j}\left(T_{i}^{-1}\left(Z^{i}+G_{i}\left(b^{i}\right)\right), x^{i 1}, x^{i 2}, . ., x^{i j-1}, x^{i j+1}, \ldots x^{i n}, b^{i}\right)
$$

If the profit function ( $\pi$ ) is defined as total revenue less total costs, then plugging in Eq. 10 and taking the partial derivative with respect to effective pollution $Z^{i}$ yields the following:

$$
\text { (11) } M A C^{i j} \equiv \frac{\partial \pi^{i}}{\partial Z^{i}}=\left[p \frac{\partial F_{i}}{\partial x^{i j}}-w^{j}\right] \frac{\partial x^{i j}}{\partial Z^{i}}
$$

where all inputs other than $x^{i i}$ are held constant. Eq. 11 is the change in profits resulting from a marginal decrease (or increase) in pollution, i.e. the MAC function for production input $i$ used by source $i$. If inputs experience diminishing returns in production and the transport function is linear ${ }^{4}$, it is straightforward to see that $M A C^{i i}$ is decreasing in $Z^{i}$. As pollution abatement increases via input $i$, the marginal cost in terms of reduced profits rises. Similarly, the MAC function for each end-of-pipe instrument is the reduction in profits per unit of pollution:

$$
M A C \quad{ }^{i b} \equiv \frac{\partial \pi^{i}}{\partial Z^{i}}=\left[\frac{c^{i}}{G_{i}^{\prime}\left(b^{i}\right)}\right] \frac{\partial b^{i}}{\partial Z^{i}}
$$

Provided that the function $G$ is concave, i.e. the effectiveness of the end-of-pipe technology declines with the amount of pollution removed, $M A C^{i b}$ is also downward sloping when plotted against pollution.

Viewing the reduction in damage or the MDC as a marginal benefit (MB), it is clear from Eq. 6 and 7 that a particular abatement technique is only used by source $i$ if the $M B$ of doing so is equal to the cost, measured in terms of either reductions in profit or the expenditures required to implement the end-of-pipe technology. Since the MB of a unit of pollution abatement does not depend on the instrument employed, the least-cost instruments are optimally used first. Otherwise, the same $M B$ could be obtained at a lower cost. It follows from Eq. 6 and 7 that the MAC is equalized not only across instruments for a particular source i but also across sources. Although the latter result has been established in the pollution abatement literature, we believe that the former has not received adequate attention.

The optimal total pollution abatement for source $i$ is determined where the source's MAC-aggregated horizontally across the $\mathrm{n}$ abatement instruments-intersects the MDC. And analogously, optimal total pollution abatement for all sources is determined where the aggregate MAC-aggregated horizon-

\footnotetext{
${ }^{4} \mathrm{~A}$ linear transport function, although perhaps a reasonable approximation over long periods of time, abstracts from changes in tides, weather, and other natural fluctuations. Such changes, even over a short period of time, can cause the transport function to evolve nonlinearly and/or discontinuously. Although beyond the scope of the current paper, allowing for dynamic fluctuations could result in nonlinear and non-monotonic MAC curves.
} 
tally across the $\mathrm{m}$ sources-intersects the MDC. Intuitively, the aggregation procedure works because an instrument/source should only abate if the MAC is less than or equal to that of other available options.

\section{Interpretation of the Substitutability Conditions}

To put the model into context, we consider how the general results are informed if one input is a perfect substitute for another regarding output but costs more and pollutes less (e.g. highly nitrogenous and cheap fertilizer like urea vs. an expensive slowrelease synthetic nitrogen fertilizer). First suppose that slow-release nitrogen fertilizer and urea are labeled as inputs 1 and 2 respectively such that $w^{1}>w^{2}$ but that the marginal pollution contribution is equal for any level of input, i.e. $\frac{\partial T_{i}}{\partial x^{i 1}}=\frac{\partial T_{i}}{\partial x^{i 2}}$ for all $x^{i i}$.

From Eq. 8, it is clear that for a single farmer, $p\left(\frac{\partial F}{\partial x^{1}}-\frac{\partial F}{\partial x^{2}}\right)=w^{1}-w^{2}>0$ which implies that $x^{1}<x^{2}$ for a concave production function. If marginal pollution is equal and the inputs are perfect substitutes, welfare is maximized by using more of the cheaper urea fertilizer.

Now suppose instead that urea is a "dirtier" input. For a linear pollution transport function $(T)$, this amounts to assuming that the coefficient in the transport matrix is larger for good 2, i.e. $\frac{\partial T}{\partial x^{1}}<\frac{\partial T}{\partial x^{2}}$. To simplify notation, we define the coefficients as $\alpha^{1}$ and $\alpha^{2}$ respectively. Rearranging Eq. 8 yields the following condition:

$$
\text { (13) }\left(p \partial F / \partial x^{1}-w^{1}\right) \alpha^{2}=\left(p \partial F / \partial x^{2}-w^{2}\right) \alpha^{1} \text {. }
$$

Letting $F_{x}=\partial F / \partial x$ for any $\mathrm{x}$, solving Eq. 13 for $\mathrm{F}_{1}$ yields.

$$
\text { (14) } F_{1}=\frac{\left(p F_{2}-w^{2}\right) \alpha^{1} / \alpha^{2}+w^{1}}{p} \text {. }
$$

An analogous term can be derived for $F_{2}$. The relative sizes of the marginal products (and hence input quantities) cannot be unambiguously determined ex ante, but we can look at which factors tend to increase/decrease the use of any particular input. It is straightforward to establish the following relationships:

(15) $\frac{\partial F_{1}}{\partial w^{1}}>0, \frac{\partial F_{1}}{\partial w^{2}}<0, \frac{\partial F_{1}}{\partial \alpha^{1}}>0, \frac{\partial F_{1}}{\partial \alpha^{2}}<0$.

The marginal product tends to be lower and the quantity of slow-release nitrogen fertilizer higher when its price is lower, the input price of urea is higher (i.e. not much lower than the clean input), the pollution coefficient for the slow-release fertilizer is lower, or the pollution coefficient for urea is higher. We can also see that the marginal product tends to be lower when the ratio of pollution coefficients (clean fertilizer: dirty fertilizer) is lower. As the ratio declines, the value of the marginal profit from urea is adjusted downward to take into account the potential substitutability with the more expensive but less nitrogenous slow-release fertilizer.

\section{Target-setting Approach}

In some instances, cultural significance of a resource is viewed as an important component of societal welfare, even though its value is extremely difficult to quantify. Or for some other reason, available information may be insufficient to even roughly estimate an environmental damage cost function. Since the socially optimal level of pollution abatement can only be identified when environmental damage is quantifiable, such circumstances require modification of the first-best management problem. One approach is to exogenously decide on the target level of pollution (e.g. through community and stakeholder meetings), and then determine the most cost-effective means of achieving the objective (e.g. Hart and Brady, 2002). Mathematically, the second-best problem can be written by replacing the damage function in the first-best problem (Eq. 5) with the constraint that pollution to the receptor is less than or equal to some constant $\bar{Z}$ :

$$
\text { (16) } \operatorname{Max}_{x^{i j}, b^{i}} \bar{L}, \bar{L}=\sum_{i=1}^{m}\left[p^{i} F_{i}\left(x^{i 1}, \ldots, x^{i n}\right)-\sum_{j=1}^{n}\left(w^{j} x^{i j}\right)-c^{i} b^{i}\right]+\lambda\left[\bar{Z}-\left(\sum_{i=1}^{m}\left(T_{i}\left(x^{i 1}, \ldots, x^{i n}\right)-G_{i}\left(b^{i}\right)\right)\right)\right]
$$

The necessary conditions for Eq. 16 are identical to Eq. 6 and 7, except with the MDC replaced by the shadow price of the pollution constraint $(\lambda)$. The implication is that one should abate using each instrument until the marginal cost of doing so is just equal to $\lambda$. In other words, following the least-cost abatement principle ensures welfare maximization, whether the pollution target is determined exogenously or endogenously by the damage cost function.

\section{Discussion}

\section{A Case Study: Nitrogen Pollution to Nearshore Ecosystems}

In what follows, we discuss how the general results derived in section 3 can be applied to a real world management situation. Specifically, the problem of nitrogen pollution to groundwater is considered.

\section{Nitrogen Pollution Overview}

In recent years, nitrogen cycles in coastal marine areas have been transformed by the increased use of chemical fertilizers, fossil fuel combustion, and other anthropogenic activities (Galloway et al., 2008). During the 20th century, the rate of global reactive nitrogen creation increased by $33-55 \%$ (Howarth, 2008), and in the United States alone, nitrogen inputs from human activity doubled between 1961 and 1997 (Howarth et al., 2002). Nitrogen and phosphorus, which are required for protein synthesis, as well as for DNA, RNA, and energy transfer, are the key limiting nutrients in most aquatic systems (Conley et al., 2009). Consequently, excess nitrogen creation has resulted in a marked increase in coastal eutrophication worldwide (Nixon, 1995; Howarth and Marino, 2006).

Although the exact relationship between nitrogen concentration and eutrophication occurrence is difficult to quantify and varies by region, there is little disagreement that the negative effects of eutrophication on marine environments-hypoxia, anoxia, habitat degradation, changes to the food-web structure, loss of biodiversity, and algal blooms (Howarth, 2008)—can be substantial. Thus, the health of coastal ecosystems can benefit from further analyses of various nitrogen reduction measures. 
In order to properly develop management strategies for the control of eutrophication, one must be able to identify the nitrogen sources and characterize the transport of nitrogen to receiving waters. Generally, three major sources contribute to nearshore nitrogen concentration: atmospheric deposition, fertilizers, and wastewater (Valiela et al., 1990; Valiela et al., 1992; Valiela et al., 1997; Valiela and Bowen 2002). In many cases, nitrogen from these sources enters the watershed away from the coast, and a considerable amount is lost to sorption and denitrification in transit to nearshore waters. In a study of Waquoit Bay, Massachusetts, for example, nitrogen losses within the watershed were estimated at $89 \%, 79 \%$, and $65 \%$ for nitrogen originating from atmospheric deposition, wastewater disposal, and fertilizer use respectively (Valiela et al., 1997). Atmospheric deposition was the largest contributor to nitrogen delivered to the watershed but the smallest contributor of effective nitrogen arriving at receiving coastal waters, whereas wastewater was the largest source of nitrogen actually reaching the estuary (nearly $50 \%$ of the total nitrogen load to the bay). Clearly, optimal management decisions will depend on both the magnitude of nitrogen loads from each source to the near-shore waters and the efficiency of nitrogen transport.

When the MAC and marginal damage cost (MDC) functions are given, it is straightforward to show that optimality requires reducing nitrogen until MAC and MDC are equal (e.g., Perman et al., 2003). For multiple nitrogen sources, equality of the aggregate MAC and the MDC determine the optimal total abatement and shadow price of nitrogen, which in turn determines sourcespecific abatement according to the individual MAC functions. Although theoretically convenient, ad hoc assumptions about the MAC curve's functional form (e.g. Hart and Brady, 2002; Laukkanen et al., 2009) are troublesome from an operational standpoint. We describe in what follows how one might apply the principles developed section 2 to the problem of nitrogen management ${ }^{5}$.

\section{Flow Versus Stock Pollution}

Economists generally draw a line between flow and stock pollution. The former occurs when damage corresponds directly to the rate at which the pollutant is discharged, while the latter occurs when damage depends on the stock or concentration of pollution built up in the environmental system. Accumulation of a stock requires that the pollutant has a positive lifespan and that the rate of emissions exceeds the rate at which the environment can assimilate or breakdown the pollution (e.g. Perman et al., 2003). However, such delineation is not always apparent. In the case of nutrient loading, damages to an estuary or bay likely depend on the stock of nitrogen, but treating nitrogen pollution as a flow may make more sense for modeling and implementation purposes. If multiple flushing events occur within the bay annually and the time step of the model is one year, then it is sensible to treat nitrogen as a fund (flow) pollutant and damages as a function of nitrogen flow.

Thus, a dynamic problem is transformed approximately into a static one, where the amount of environmental damage is related to the amount of nitrogen flowing into the receptor area in a given period.

\section{Optimal Nitrogen Management}

We consider nitrogen loading to the nearshore environment from two sources: fertilizer used for agriculture or landscaping and sewage from wastewater treatment plants. Nitrogen leaching into groundwater from fertilizer can be reduced by substituting clean inputs for dirty ones. This might entail, for example, using slow-release nitrogen fertilizer and applying it more frequently in smaller doses. However, cleaner fertilizers tend to be more expensive, and improving the frequency and accuracy of applications increases labor costs. Leaching from fertilizer can also be controlled via an end-of-pipe technology such as a subsurface nitrate barrier (e.g. biofilm or woodchips) designed to remove nitrogen from groundwater as it flows subterraneously toward the bay (Robertson et al., 2007). In the case of sewage, we suppose that wastewater can undergo an additional endof-pipe treatment such as bacterial denitrification after being processed at the treatment facility.

The general pollution abatement framework (Eq. 1) can be applied to the nitrogen loading problem for $m=2$ and $n=5$. The amount of nitrogen entering the groundwater from fertilizer can be reduced by adjusting three production inputs (clean fertilizer, dirty fertilizer, irrigation water) and/or employing the nitrate barrier. The nitrogen from wastewater can similarly be reduced through denitrification, bringing the total number of abatement instruments to five. From Eq. 6, the loss in profit resulting from a marginal reduction of each input should be equal to the marginal damage cost of leached nitrogen at the optimum, taking into account potential sorption and natural denitrification in transit to the nearshore environment. From Eq. 7, those MACs should also be equal to the cost of employing a subsurface nitrate barrier. If the equimarginality conditions did not hold, then total nitrogen loading could be reduced without increasing the cost, which cannot be optimal.

At the same time, the MACs should be equal across sources. Since only one abatement instrument is available for wastewater, the equimarginality condition need only be extended to include the marginal cost of denitrification. Supposing that data is available to quantify each of the MAC curves and to parameterize a damage function, the optimal quantities of abatement for each instrument (and hence each source) can be determined through the aggregation procedure described in section 2. Depending on the shapes of the MAC and MDC curves, it may be optimal not to abate using one or more instruments. For example, if the cost of sewage denitrification is very expensive, all of the abatement will occur in the agriculture/landscaping sector, as determined by the relative MACs for the farm production inputs and the nitrate barrier.

\footnotetext{
${ }^{5}$ Goetz and Zilberman (2010) develop a similar management framework to address the problem of phosphorus runoff. They do not, however, derive or conjecture a MAC function in solving their model.
} 


\section{Endogenous Prices, Dynamic Considerations, and Discrete Choices}

In resource economics, exogenous prices are often specified to represent the demand side of a management problem (e.g. fisheries), such that deriving appropriate supply side conditions allow one to "close the model".

Such a specification is not amenable to all management situations, however. For instance, if the irrigation water in our previous example is drawn from a groundwater aquifer, then the water price should be endogenous and account for two effects: (i) the marginal user cost (MUC) or the change in present value associated with a marginal increase in today's consumption of water, and (ii) the marginal externality cost (MEC) generated from the leached nitrogen that ultimately flows subterraneously to nearshore ecosystems.

In a general dynamic model, applying fertilizers adds to the base level of nitrogen in the ground (although more intensive cultivation holding fertilizer constant depletes soil nitrogen), and irrigation depletes the nitrogen stock and increases stock-toflow $\mathrm{N}$-pollution in the bay. Thus in every period, the stock of soil nitrogen is approximately some constant, plus the amount of fertilizer added, minus the amount leached into irrigation water. Underpriced groundwater, which does not account for MUC and MEC, results in higher rates of irrigation and consequently greater $\mathrm{N}$-flux. Correct pricing for groundwater is given by $\mathrm{P}=$ $c+$ MUC + MEC, where MUC is a function of the groundwater stock, and MEC is a function of the nitrogen stock (e.g., Pongkijvorasin et al., 2006).

In addition, irrigation technology can vary, such that the question becomes not just how much, but also how frequently and by what means. In that sense, modeling irrigation is analogous to the problem of choosing between expensive but low-polluting methods and cheap but high-polluting methods for burning coal. Applying large amounts of water infrequently is less costly than applying less water more frequently but is more polluting because more excess water leaches nitrogen and infiltrates into the underlying groundwater aquifer. A simple way to capture the idea is to allow for a discrete choice of whether or not to implement a trickle irrigation system. Without the irrigation system and abstracting from end-of-pipe abatement, it may make sense to achieve the optimal level of nitrogen $\left(\mathrm{N}^{*}\right)$ by reducing the use of all three inputs: water (1), clean fertilizer (2), and dirty fertilizer (3). In Figure 1, reducing irrigation lowers nitrogen to $N_{1}$, reducing the use of slow-release fertilizer further decreases nitrogen to $\mathrm{N}_{2}$, and reducing the use of urea decreases nitrogen to $\mathrm{N}^{*}$. Installing the irrigation system shifts $M A C^{1}$ downward; more efficient irrigation means that profits are reduced by less for a given decrease in water applied. The input price of water increases by the user cost of capital, but the change would be more than offset by the increase in production efficiency. Otherwise, the present value could be increased by choosing not to install the irrigation system. The trickle irrigation system allows abatement via reduced water input to largely replace abatement via fertilizer reduction. As drawn, Figure 1 suggests that the desired level of abatement can be achieved entirely by urea and irrigation reduction.

Implementing trickle irrigation, however, will only solve part of the problem if water is underpriced at the outset. While it will help to increase the efficiency of water that is used for irrigation, the input price still fails to reflect the true scarcity value of water. In other words, although groundwater use is likely to decline, it will still be over-consumed relative to the optimum.

\section{Second-best Issues and Implementation}

The first-best outcome can be achieved if the prices of water and nitrogen-contribution to flux at the bay are set at their firstbest levels, i.e. at the levels that compel farmers to account for the MUC and MEC of each production input. In reality, however, data on nitrogen contribution may not be available and measuring it may be difficult or prohibitively costly. Consequently, alternative policy instruments should be considered for achieving

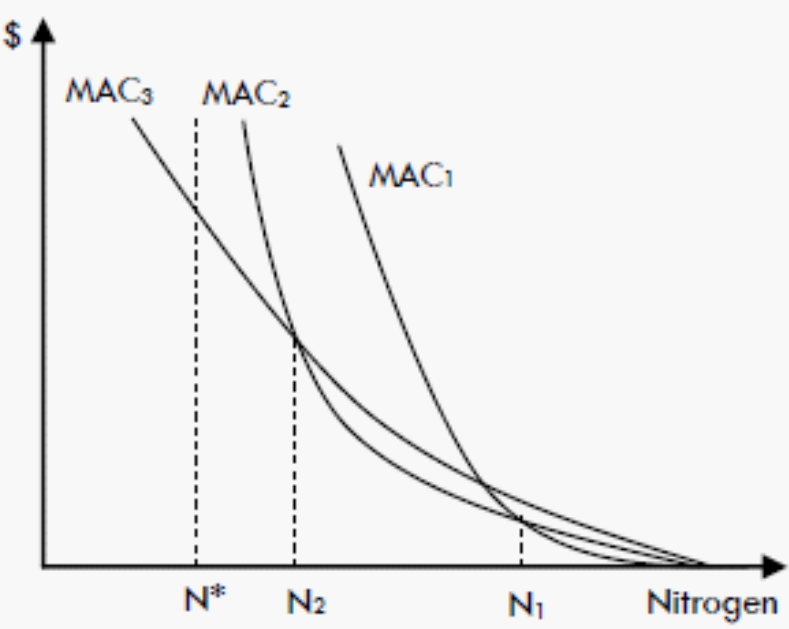

Abate with Abate with Abate with instrument 3 instrument 2 instrument 1

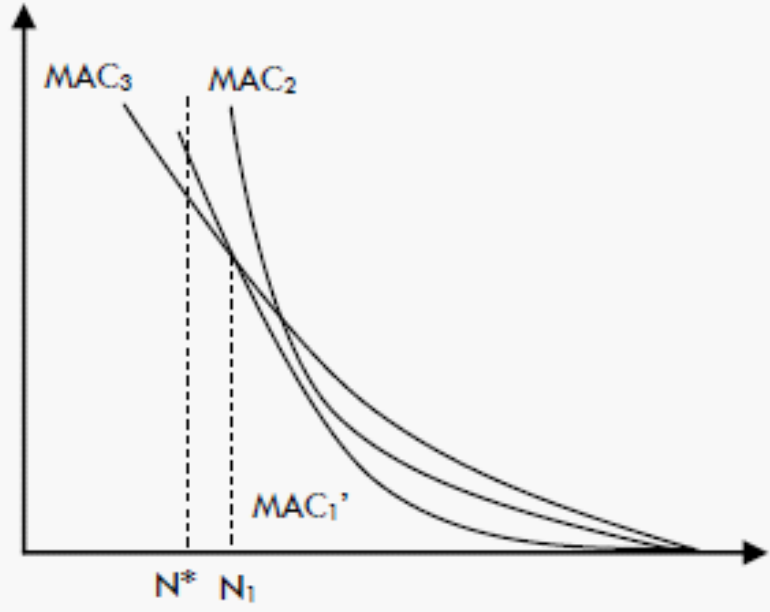

Abate with instrument 3
Abate with instrument 1

Figure 1. Decomposition of optimal nitrogen abatement with (left) and without (right) trickle irrigation. 
pollution-reduction goals, e.g. a tax on high-emission fertilizer such as urea combined with a price structure for water related to both the amount and frequency. For the latter, this means that the same amount of water is less expensive if applied more uniformly. Subsidies for the use of certain irrigation technologies such as trickle irrigation could proxy for application uniformity.

If the optimality conditions (Eq. 6) reveal that one of the inputs such as urea should be zero, the corresponding tax would have to be prohibitively high. Inasmuch as such a tax is a de facto ban on the input, an actual ban may be a more cost-effective (albeit perhaps politically unfavorable) policy. For example, the cost of actively enforcing the tax on hundreds or thousands of retailers and suppliers throughout the region may exceed the cost of inspecting incoming fertilizer shipments at fewer points of entry.

\section{Conclusions and Research Extensions}

Inasmuch as the functional forms of pollution abatement cost functions are often assumed rather than derived, we develop a method for constructing MAC functions, using information from an optimization problem, whose objective is to maximize social benefits from production, net of environmental damage costs generated from those production activities. We derive the MAC function for multiple pollution sources when multiple abatement instruments are available. The optimal solution is characterized by ordering instruments in reverse order of their MAC, which implies that multiple controls are implemented simultaneously only when their MACs are equal to each other, as well as to the MDC. The general result of least-MAC first extends to both the problems of optimally abating with multiple instruments across multiple pollution sources, as well as maximizing social net benefits when the pollution target is exogenously determined.

We then discuss how the framework can be applied to the problem of managing nitrogen pollution to nearshore environments. When multiple terrestrial sources contribute nitrogen to groundwater and production input prices can be taken as exogenous, abatement is determined according to the relative magnitudes of the marginal abatement cost curves in a given period as described in the general model. In some cases, however, input prices should be determined endogenously. If irrigation from groundwater sources is considered as an input to farm production, then the prices of groundwater and nitrogen should be determined simultaneously because the marginal externality cost of irrigation is a function of the stock of soil nitrogen. To address this problem, the static framework would need to be extended to include resource dynamics.

The basic framework could also be extended to the case where demand is growing exogenously over time. In the case of agricultural production for example, the MAC curves will be shifting upward over time if the demand for fertilizer is increasing. As a result, optimal total abatement, as well as the decomposition of abatement between instruments and across sources will also evolve dynamically. Generally, abatement instruments which are not initially attractive may become cost effective as the MAC curves for fertilizer rise. Thus, optimal switching between instruments is possible, as long as the equimarginality conditions (Eq. 6 and 7) hold in every period.
An analogous extension can be made when the damage cost curve is shifting over time. This may happen, for example, if climate change increases the occurrences of damaging processes (e.g. eutrophication) for a given level of pollution at the receptor. Like in the case of growing demand, rising marginal damage costs increase optimal total abatement over time. However, it does not encourage reduction in abatement from particular instruments; rather, abatement may become positive for previously unused instruments as one moves up the optimal aggregate MAC curve.

\section{Acknowledgements}

This research was funded in part by NSF EPSCoR Grant No. EPS-0903833.

\section{References}

Bovenberg AL and RA de Mooij (1994) Environmental Levies and Distortionary Taxation. American Economic Review 84( 4): 1085-1089.

Bovenberg AL and LH Goulder (1996) Optimal Environmental Taxation in the Presence of Other Taxes: General-Equilibrium Analyses. American Economic Review 86(4): 985-1000.

Conley DJ, HW Paerl, RW Howarth, DF Boesch, SP Seitzinger, KE Havens, C Lancelot, and GE Likens (2009) Controlling Eutrophication: Nitrogen and Phosphorus. Science 323: 1014-1015.

Fullerton D, SP McDermott, and JP Caulkins (1997) Sulfur Dioxide Compliance of a Regulated Utility. Journal of Environmental Economics and Management 43: 32-53.

Galloway JN, AR Townsend, JW Erisman, M Bekunda, Z Cai, JR Freney, LA Martinelli, SP Seitzinger, and MA Sutton (2008) Transformation of the Nitrogen Cycle: Recent Trends, Questions, and Potential Solutions. Science 320: 889-892.

Goetz RU and D Zilberman (2000) The dynamics of spatial pollution: The case of phosphorus runoff from agricultural land. Journal of Economic Dynamics and Control 24: 143-163.

Hart R and M Brady (2002) Nitrogen in the Baltic Sea - policy implications of stock effects. Journal of Environmental Management 66: 91-103.

Howarth RW, EW Boyer, WJ Pabich, and JN Galloway (2002) Nitrogen Use in the United States from 1961-2000 and Potential Future Trends. Ambio 31(2): 88-96.

Howarth RW and R Marino (2006) Nitrogen as the limiting nutrient for eutrophication in coastal marine ecosystems: Evolving views over three decades. Limnology and Oceanography 51(1): 364-376.

Howarth RW (2008) Coastal nitrogen pollution: A review of sources and trends globally and regionally. Harmful Algae 8: 14-20.

Johnson AG, CR Glenn, WC Burnett, RN Peterson, and PG Lucey (2008) Aerial infrared imaging reveals large nutrient-rich groundwater inputs to the ocean. Geophysical Research Letters 35: L1 5606.

Laukkanen M, P Ekholm, A Huhtala, H Pitkanen, M Kiirikki, P Rantanen, and A Inkala (2009) Integrating Ecological and Economic Modeling of Eutrophication: Toward Optimal Solutions for a Coastal Area Suffering from Sediment Release of Phosphorus. Ambio 38(4): 225 235.

McKitrick R (1999) A Derivation of the Marginal Abatement Cost Curve. Journal of Environmental Economics and Management 37: 306-31 4.

Metcalf GE (2009) Market-Based Policy Options to Control U.S. Greenhouse Gas Emissions. The Journal of Economic Perspectives (Climate Change Symposium) 23(2): 5-27.

Montgomery WD (1972) Markets in licenses and efficient pollution con- 
trol programs. Journal of Economic Theory 5(3): 395-418.

Murray BC, RG Newell, and WA Pizer (2009) Balancing cost and emissions certainty: An allowance reserve for cap-and-trade. Review of Environmental Economics and Policy 3(1): 84-103.

Nordhaus WD (2008) A Question of Balance: Weighing the Options on Global Warming Policies. Yale University Press, New Haven, CT.

Nixon SW (1995) Coastal marine eutrophication: a definition, social causes, and future concerns. Ophelia 41: 199-219.

Perman R, Y Ma, J McGilvray, and M Common (2003) Natural Resource and Environmental Economics. Pearson Addison Wesley, New York.

Pongkijvorasin S, B Pitafi, and J Roumasset (2006) Pricing resource extraction with stock externalities. Selected Paper prepared for presentation at the American Agricultural Economics Association Annual Meeting, Long Beach, California, July 23-26, 2006.

Robertson W, C Ptacek, and S Brown (2007) Geochemical and Hydrogeological Impacts of a Wood Particle Barrier Treating Nitrate and Perchlorate in Ground Water. Ground Water Monitoring \& Remediation 27: 85-95.

Valiela I, J Costa, K Foreman, JM Teal, B Howes, and D Aubrey (1990)
Transport of Groundwater-Borne Nutrients from Watersheds and Their Effects on Coastal Waters. Biogeochemistry 10(3): 177-197.

Valiela I, K Foreman, M LaMontagne, D Hersh, J Costa, P Peckol, B DeMeo-Andreson, C D'Avanzo, M Babione, CH Sham, J Brawly, and K. Lajtha (1992) Couplings of Watersheds and Coastal Waters: Sources and Consequences of Nutrient Enrichment in Waquoit Bay, Massachusetts. Estuaries 15(4): 443-457.

Valiela I, G Collins, J Kremer, K Lajtha, M Geist, M Seely, J Brawley, and CH Sham (1997) Nitrogen Loading from Coastal Watersheds to Receiving Estuaries: New Method and Application. Ecological Applications 7(2): 358-380.

Valiela I and JL Bowen (2002) Nitrogen sources to watersheds and estuaries: role of land cover mosaics and losses within watersheds. Environmental Pollution 118: 239-248.

Yiridoe EK and A Weersink (1998) Marginal Abatement Cost of Reducing Groundwater-N Pollution with Intensive and Extensive Farm Management Choices. Agricultural and Resource Economics Review 27(2): 169-185. 